\title{
ENTRE A ESCOLA E O RIO: vivências e desafios da educação infantil ribeirinha
}

\author{
Ana Paula Lima Carvalho de Oliveiral \\ lolete Ribeiro da Silva² \\ Jocicleia Souza Printes ${ }^{3}$
}

\section{RESUMO}

Este texto carrega os olhares e as escutas de encontros vividos em uma escola ribeirinha na comunidade Esperança, localizada no igarapé do Tiú, rio Tarumã Açu, afluente esquerdo do rio Negro, na cidade de Manaus-AM. É fruto de uma pesquisa de mestrado e das inquietações e percepções que dela emergiram. Aqui, apontamos os caminhos narrados pelas vivências diárias dos sujeitos em um contexto de educação formal à beira do rio e os desafios diários da construção identitária da educação do campo, com suas características próprias que marcam a formação de crianças e professores. Nosso olhar de análise foi construído através da teoria Histórico-Cultural em uma pesquisa participante, onde os encontros entre crianças e professora de uma turma de educação infantil fizeram emergir as especificidades de fazer educação no Amazonas em áreas onde o rio é o caminho que leva à escola e dele emergem as condições de acesso e permanência na instituição ao longo do ano. A experiência vivida com o coletivo de crianças pequenas ribeirinhas anuncia, mais uma vez, a necessidade de pensar a pesquisa com o compromisso de narrar essas vozes e assegurar que elas serão ouvidas em sua inteireza.

Palavras-chave: Educação Ribeirinha. Educação Infantil. Teoria Histórico-Cultural.

\footnotetext{
1 Mestra em Educação pela Faculdade de Educação da Universidade Federal do Amazonas, na Linha de Pesquisa Processos Educativos e Identidades Amazônicas; Pedagoga da Divisão de Educação Infantil da Secretaria Municipal de Educação - AM, Brasil. Orcid iD: https://orcid.org/0000-0002-3654-9447. E-mail: anaamz.oliveira@gmail.com

2 Doutora em Psicologia; Professora Titular da Faculdade de Psicologia da Universidade Federal do Amazonas; Professora do Programa de Pós-Graduação em Educação PPGE/UFAM e do Programa de Pós-Graduação em Psicologia PPGPSI/UFAM - AM, Brasil. Orcid iD: https://orcid.org/0000-0002-9416-6866. E-mail: iolete.silva@gmail.com

3 Doutora em Educação pela Faculdade de Educação da Universidade Federal do Amazonas, na Linha de Pesquisa Formação e Práxis do(a) Educador(a) Frente aos Desafios Amazônicos; Professora da Universidade do Estado do Amazonas, no Centro de Estudos Superiores de Tabatinga - AM, Brasil. Orcid iD: https://orcid.org/0000-0002-6065-6058. E-mail: jprintes@vea.edu.br
} 


\title{
BETWEEN SCHOOL AND RIVER: experiences and challenges of early childhood
}

\author{
education on the riverbank
}

\begin{abstract}
This text takes the looks and listening of encounters lived in a riverside school in the Esperança community, located in the Tiú stream, Tarumã Açu River, a left tributary of the Negro River, in the city of Manaus-AM. It is the result of a master's research and the concerns and perceptions that have emerged from it. Here, we point out the paths narrated by the daily experiences of the subjects in a context of formal education by the river and the daily challenges of the identity construction of country education, with its own characteristics that mark the education of children and teachers. Our analysis view was constructed through the Historical-Cultural theory in a participant research, where the meetings between children and teacher of a early childhood education class brought out the specificities of doing education in the Amazon in areas where the river is the path that leads to school and from it emerge the conditions of access and permanence in the institution throughout the year. The experience lived with the collective of small riverside children announces, once again, the need to think about research with the commitment to narrate these voices and ensure that they will be heard in their entirety.
\end{abstract}

Keywords: Riverside Education. Early Childhood Education. Historical-Cultural Theory.

\section{ENTRE LA ESCUELA Y EL RÍO: experiencias y retos de la educación infantil ribereña}

\section{RESUMEN}

Este texto lleva las miradas y la escucha de encuentros vividos en una escuela ribereña de la comunidad de Esperança, ubicada en el Tiú igarapé, río Tarumã Açu, afluente izquierdo del río Negro, en la ciudad de Manaus-AM. Es el resultado de una investigación de maestría y de las inquietudes y percepciones que surgieron de ella. Aquí se señalan los caminos narrados por las experiencias cotidianas de los sujetos en un contexto de educación formal a la orilla del río y los desafíos cotidianos de la construcción identitaria de la educación en el campo, con características propias que marcan la educación de los niños y los maestros. Nuestro análisis se construyó a través de la teoría Histórico-Cultural en una investigación participante, donde los encuentros entre los niños y la maestra de una clase de educación infantil hicieron emerger las especificidades de hacer educación en la Amazonía en zonas donde el río es el camino que lleva a la escuela y de él emergen las condiciones de acceso y permanencia en la institución a lo largo del año. La experiencia vivida con el grupo de pequeños ribereños anuncia, una vez más, la necesidad de pensar la investigación con el compromiso de narrar estas voces y asegurar que sean escuchadas en su totalidad.

Palabras clave: Educación en los Ríos. Educación Infantil. Teoría Histórico-Cultural. 


\section{INTRODUÇÃO}

Nossa discussão parte de uma pesquisa de campo realizada durante o curso de mestrado, em uma escola municipal na comunidade Nova Esperança, que atende às etapas da Educação Infantil e Ensino Fundamental anos iniciais, localizada no igarapé do Tiú, no rio Tarumã Açú (afluente esquerdo do rio Negro), na zona ribeirinha de Manaus. As crianças foram os sujeitos centrais desta discussão, que objetivou a compreensão dos significados construídos por elas sobre o seu processo educativo em uma escola ribeirinha (OLIVEIRA, 2018).

Para além da proposta inicial da pesquisa, outros sentidos foram se construindo nas relações vivenciadas entre o rio e escola. Cada encontro produzia ampliações das percepções e sentidos sobre o processo educativo de crianças que se relacionam direta e cotidianamente com a natureza e que tem nas águas as referências da organização da vida: entre cheias e vazantes ${ }^{4}$, o ritmo ribeirinho se constrói cotidianamente através dos rios.

Os diálogos construídos ao longo dos encontros trouxeram apontamentos para pensarmos a formação vivida entre o cotidiano e não cotidiano do trabalho do professor. Heller $(2000,1987)$ nos oferece elementos para compreender os caminhos possíveis trilhados pelos professores no seu processo formativo diante das suas condições concretas de vida.

Neste artigo, pretendemos produzir uma narrativa sobre os caminhos dos sujeitos e suas vivências diárias em um contexto de educação formal à beira do rio e os desafios diários da construção identitária da educação do campo, com suas características próprias que marcam a formação de crianças e professores. Para isso, acompanhamos as relações vivenciadas em uma turma de pré-escola dentro de uma trama onde o entendimento sobre a organização social das infâncias ribeirinhas é atravessado pelas relações urbanas, tão distantes e tão próximas de forma simultânea.

\footnotetext{
4 As cheias dos rios estão relacionadas ao período chuvoso, que geralmente ocorre no primeiro semestre do ano, atingindo seu nível máximo, geralmente, em junho. Logo depois, as águas estabilizam e a vazante começa, que é quando as águas dos rios começam a descer, atingindo seu nível mínimo meados de outubro. A diferença entre o pico de cheia e a vazante gira em torno de 10 metros.
} 
Para pautar nossas inquietações, iniciamos contextualizando a população ribeirinha, a escola e as relações com a cultura e a formação da identidade, fazendo um exercício a partir de leituras e experiências sobre quem são essas pessoas e como elas se organizam socialmente. Em seguida, apontamos as especificidades da oferta e demanda de educação infantil ribeirinha na cidade de Manaus para, então, refletirmos sobre as vivências e os desafios vividos por crianças e professores na educação infantil ribeirinha.

\section{POPULAÇÃO RIBEIRINHA E A ESCOLA: CULTURA E IDENTIDADES}

A educação infantil do/no campo inclui a diversidade de infâncias, povos e populações que vivem nos territórios rurais do país. Reconhecendo essa característica, a Resolução 02/2008, do Conselho Nacional de Educação, que estabelece diretrizes, normas e princípios para a Educação Básica do Campo, define as populações rurais como: agricultores familiares, extrativistas, pescadores artesanais, ribeirinhos, assentados e acampados da reforma agrária, quilombolas, caiçaras e outros.

As Diretrizes Curriculares Nacionais para a Educação Infantil (Resolução no 5, de 17 de dezembro de 2009) também tratam das especificidades da proposta pedagógica para as infâncias do campo, quando no Art. 8 desse documento é afirmado que:

As propostas pedagógicas da Educação Infantil das crianças filhas de agricultores familiares, extrativistas, pescadores artesanais, ribeirinhos, assentados e acampados da reforma agrária, quilombolas, caiçaras, povos da floresta, devem:

I - reconhecer os modos de vida no campo como fundamentais para a constituição da identidade das crianças moradoras em territórios rurais;

II - obter vinculação inerente às realidades dessas populações, suas culturas, tradições e identidades, assim como as práticas ambientalmente sustentáveis;

III - flexibilizar, se necessário, calendário, rotinas e atividades respeitando as diferenças quanto à atividade econômica dessas populações;

IV - valorizar e evidenciar saberes e o papel dessas populações na produção de conhecimentos sobre o mundo e sobre o ambiente natural;

$\checkmark$ - prever a oferta de brinquedos e equipamentos que respeitem as características ambientais e socioculturais da comunidade. 
O reconhecimento da educação do/no campo e das infâncias do campo são conquistas legais importantes e necessárias para que esses modos de vida sejam valorizados em sua organização social. Estas ações precisam fortalecer as identidades de cada povo na luta constante contra a invisibilidade de sua identidade e cultura.

Os ribeirinhos, povos que se referem à chamada população tradicional da Amazônia, assim são referenciados pela maneira como se comunicam, como representam e fazem uso dos lugares e tempos de suas vidas na relação com a natureza, sobretudo com a água. Para Chaves (2001, p. 78), os agentes sociais que identificam os ribeirinhos podem ser assim caracterizados:

[...] vivem em agrupamentos comunitários com várias famílias, localizados, como o próprio termo sugere, ao longo dos rios e seus tributários (lagos). A localização espacial nas áreas de várzea, nos barrancos, os saberes sócio históricos que determinam o modo de produção singular, o modo de vida no interior das comunidades ribeirinhas, concorrem para a determinação da identidade sociocultural desses atores.

Na obra Amazônia: formação social e cultural, Benchimol (2009) esclarece que os ribeirinhos compõem a população da Amazônia tradicional, habitando os baixos rios e o beiradão da calha central, sobrevivendo em todos os pequenos sítios, povoados, vilarejos e cidades, foram se estabelecendo ao longo do rio Amazonas e seus afluentes. $O$ autor ainda completa a caracterização da população desses lugares, discorrendo:

Eram e ainda são índios puros, meio-índios, índios-caboclos, caboclos, meio-caboclos, caboclo-índios de diferentes grupos étnicos e tipos de miscigenação genética, resultado do cruzamento racial com os colonizadores, imigrantes nordestinos e outros povos. Uma herança cultural indígena aculturada pela convivência com esses novos elementos humanos portadores de outros valores, hábitos e costumes, que foram sendo incorporados pelas necessidades de sobrevivência ao longo dos tempos e dos ciclos econômicos (BENCHIMOL, 2009, p. 38). 
Apesar do que o termo tradicional pode nos remeter, em Manaus já não se pode pensar os ribeirinhos como um povo isolado das dinâmicas de outras áreas da cidade. Eles interagem com outras formas de vida da cidade por meio do rio, seja para buscar insumos para suas casas nos mercados da área urbana, seja para participarem de eventos sociais que não acontecem em contexto ribeirinho, seja acessando, em alguns lugares, sinais de TV via antena parabólica.

Essa dinâmica tem influência nas formas de ensinar e aprender no contexto da escola, em como se organizam os currículos para as crianças ampliarem suas experiências. Sobre esse ponto, carregamos uma inquietação ao longo dos encontros: as escolas do campo, em específico as das áreas ribeirinhas, traduzem nas suas rotinas pedagógicas os modos de vida próprio do espaço e lugar das comunidades onde estão situadas?

Historicamente, os processos colonizadores pretendiam intensificar uma cultura de homogeneização para validar uma estrutura de sociedade e de valores, suprimindo qualquer diferença. Nesse movimento, reduziu-se então a diversidade pedagógica e, com ela, a representatividade de culturas brasileiras no espaço escolar - fator que contribuiu sobremaneira para o aumento da desigualdade no Brasil (ARROYO, 2008).

A defesa de uma formação cultural e identitária que amplie a capacidade das crianças de conhecerem a si mesmo e ao mundo precisa ser prioridade nos processos de elaboração das condições de aprendizagem e desenvolvimento, porque esse processo não ocorre em uma relação natural, mas nas relações que a criança estabelece com o meio social e cultural. O modo como vivemos, as situações que enfrentamos, a nossa troca aberta com o mundo faz as experiências vividas provocarem transformações no ambiente e no próprio sujeito.

Pensar uma escola ribeirinha assentada sobre uma identidade e cultura própria demanda respeito e conhecimento de todas as instâncias ligadas a ela, que perpassa desde a organização do calendário, composição de turmas, seleção dos professores e funcionários, envio de merenda, material, manutenção e transporte. 
Para além das condições físicas, é preciso cuidado em como a proposta pedagógica se efetiva, de forma a garantir o envolvimento das crianças nas atividades da escola, permitindo a construção de significados em relação ao seu mundo, capazes de possibilitar vivências éticas e estéticas com outras crianças e grupos culturais, alargando seus padrões de referência e de identidade (BRASIL, 2009a).

\section{AS ESPECIFICIDADES DA DEMANDA E OFERTA DA EDUCAÇÃO INFANTIL NAS ÁREAS RIBEIRINHAS EM MANAUS-AM}

A Prefeitura Municipal de Manaus, por meio da Secretaria Municipal de Educação - SEMED, coordena 492 unidades com oferta de educação infantil e ensino fundamental. Destas, 248 atendem a primeira etapa, assim organizadas: 18 prédios de oferta exclusiva para bebês e crianças público da creche, 111 unidades de CMEl - Centro Municipal de Educação Infantil (com oferta prioritária de pré-escola) e 119 unidades mistas, que são escolas de ensino fundamental que oferecem turmas de pré-escola pela alta demanda comunitária.

As unidades estão organizadas em 07 Divisões Distritais Zonais (DDZ), conforme as zonas geográficas da cidade: zona Sul, zona Centro-Sul, zona Oeste, zona Leste I, zona Leste II, zona Norte e zona Rural. As matrículas de bebês e crianças nas DDZ em Manaus estão assim organizadas:

Tabela 1: Crianças matriculadas na Educação Infantil na rede municipal de Manaus

\begin{tabular}{|l|l|l|}
\hline DDZ & Creche & Pré-Escola \\
\hline Sul & 1.792 & 8.527 \\
\hline Oeste & 566 & 8.319 \\
\hline Norte & 353 & 7.906 \\
\hline Centro Sul & 936 & 5.561 \\
\hline Leste I & 458 & 7.385 \\
\hline Leste II & 865 & 6.444 \\
\hline Rural & $\mathbf{4 2}$ & $\mathbf{1 . 6 1 7}$ \\
\hline Total & 5.012 & 45.759 \\
\hline
\end{tabular}


Fonte: Divisão de Informação e Estatística/SEMED - Abril/2020.

A Divisão Distrital da Zona Rural atende a área Rodoviária e as comunidades do rio Amazonas e do rio Negro, coordenando 87 unidades de ensino. No entanto, há somente um CMEl, dado que sinaliza a necessidade de repensar as políticas públicas de oferta e matrícula para áreas menos populosas. Em sua maioria, as turmas de educação infantil são ofertadas nas escolas do ensino fundamental (escolas mistas), sejam elas em turmas exclusivas (apenas crianças de até 5 anos e 11 meses) ou em turmas multisseriadas (crianças da educação infantil e do ensino fundamental juntas na mesma sala). São essas condições que justifica termos 42 matrículas na fase creche e 1617 matrículas na fase pré-escola tendo apenas uma unidade de CMEl na referida DDZ.

Nas áreas ribeirinhas do rio Amazonas e rio Negro, a realidade das salas multisseriadas ocorre com mais frequência em função das distâncias entre as comunidades e demanda das localidades na beira dos rios, consideradas insuficientes para compor uma turma. Há comunidades que para determinado ano de matrícula, há uma média de três a cinco crianças para a educação infantil. Para garantir o acesso à educação escolar, formam-se turmas multisseriadas, somando-as com as crianças do ensino fundamental, formando turmas com média de 8 a 15 crianças.

A especificidade dos sujeitos da zona rural e os marcos legais que normatizam a oferta e organização da educação do campo nos chama a discussão. Por um lado, há a determinação de que, em hipótese alguma, serão agrupadas crianças das turmas de educação infantil e ensino fundamental num mesmo espaço 5 . Por outro lado, a especificidade dos grupos etários da zona rural é diferente da zona urbana, na qual a organização de turmas por grupo etário acontece.

As comunidades ribeirinhas têm menor densidade populacional que a área urbana e por isso, a quantidade de crianças de um mesmo grupo etário, por vezes, não alcança um número que atenda aos critérios de

\footnotetext{
${ }^{5}$ Resolução CNE/CEB Nº 2 de 29 de abril de 2008.
} 
formação de turma da SEMED. Para atender ao direito que as crianças têm de acesso à educação, a quantidade que houver do grupo etário da educação infantil se soma ao grupo etário do ensino fundamental para que a turma seja formada, possibilitando assim, o envio de professores e insumos para o funcionamento das diferentes etapas.

Essas decisões não dispõem de fundamentação legal para tais critérios, já que não se tem determinado número mínimo de crianças por turma em nenhuma legislação nacional. O que temos é o oposto disso: orientações do MEC no Parecer CNE/SEB N 20/2009 sobre o quantitativo limite de bebês e crianças nas turmas de educação infantil: "recomenda-se a proporção de 6 a 8 crianças por professor (no caso de crianças de zero e um ano), 15 crianças por professor (no caso de criança de dois e três anos) e 20 crianças por professor (nos agrupamentos de crianças de quatro e cinco anos)" (BRASIL, 2009a, p. 13).

Estas decisões também desconsideram as diversidades da educação do campo e das especificidades pedagógicas de cada etapa, uma vez que as necessidades das crianças pequenas são diferentes das crianças do ensino fundamental. É um trabalho desafiador e complexo para o professor que atende às turmas multisseriadas nesse contexto. A organização social dos espaços, tempo e agrupamentos precisam considerar a realidade do campo sem a intenção de ajustá-la aos moldes urbanos. O parecer CNE/SEB No 20/2009 orienta que:

$\mathrm{Na}$ discussão sobre as diversidades, há que se considerar que também a origem urbana das creches e pré-escolas e a sua extensão como direito a todas as crianças brasileiras remetem à necessidade de que as propostas pedagógicas das instituições em territórios não-urbanos respeitem suas identidades.

O planejamento das atividades de Educação Infantil da escola onde a pesquisa foi realizada ocorre a cada trinta dias letivos e são norteados pela Proposta Pedagógico-Curricular de Educação Infantil da SEMED Manaus - PPCEl (2016), elaborada no ano de 2013 a partir das orientações 
das Diretrizes Curriculares Nacionais para a Educação Infantil (Resolução no 5 de 17 de dezembro de 2009), revisada e ampliada no ano de 2016.

A construção da PPCEl foi coordenada pela Divisão de Educação Infantil da SEMED/Manaus e contou com a colaboração da Divisão de Desenvolvimento Profissional do Magistério (setor responsável pela formação continuada de professores) e com assessoras de todas as DDZ, além da participação de professores e crianças. A PPCEl chama o tema à discussão quando aponta que:

A Educação Infantil do Campo apresenta especificidades em seu contexto local, peculiaridades que devem ser usadas como caminhos do aprendizado significativo para a criança pequena. [...] O campo ou zona rural apresenta um espaço diversificado de ações e criações, natural ou humanizado, podendo ser explorado em todo seu contexto, valorizando a cultura e a identidade da criança pequena. Explorar o espaço do campo, dentro do processo de aprendizagem infantil, conduzirá a criança a novas indagações, curiosidades que a levará a descobertas inéditas, voltadas a contextualização do seu modo de vida campestre, posteriormente abrindo caminhos para que a mesma esteja situada não somente no local onde mora, mas também no planeta em que vive. Desta maneira, o aprendizado passa a ter significado, à medida que o próprio professor oportuniza vias de conhecimento dentro dos mais diversos espaços rurícolas. É importante reafirmar que, como toda criança, aquela que vive no campo deve ter seu contexto valorizado e, sobretudo, ampliado pelo contato com as diferentes culturas produzidas socialmente: ensinar 0 novo é atuar sobre o desenvolvimento (MANAUS, 2016, p. 104).

Para a PPCEI (MANAUS, 2016), professores da educação infantil do campo precisam organizam o espaço, o tempo e os materiais para que ocorra a aprendizagem e o desenvolvimento da criança na intenção da valorização da cultura e do lugar onde vive, mas também que possibilite o alargamento de suas referências éticas e estéticas, ampliando o contato com as produções culturais de outros espaços.

Segundo Silva e Pasuch (2012), conhecer o processo de construção da identidade individual e coletiva torna possível o entendimento de uma educação infantil ribeirinha que desenvolve uma visão positiva do grupo ao qual pertence, que não se colocam em subalternidade, que valoriza as tradições culturais com seu grupo de referência e que considera o seu 
espaço como lugar de vida e produção humana. É a partir dessas situações concretas de vida que devem ser desenvolvidos os processos educativos nos espaços formais de educação do/no campo.

\section{ENTRE O RIO E A ESCOLA: TESSITURAS DE MOVIMENTO, TEMPOS E RELAÇÕES}

A criança ribeirinha sujeito dessa realidade, constrói o conhecimento de si e do mundo nas relações e experiências vividas com o seu grupo social, por isso, é importante que a escola seja um local onde as infâncias do campo tenham tempo e espaço para as vivências que Ihes oportunizem conhecer

[...] as formas como suas comunidades nomeiam o mundo, festejam, cantam, dançam, contam histórias, produzem e preparam seus alimentos. Temos o desafio de construir creches/pré-escolas com a cara do campo, mas também com o 'corpo e a alma' do campo, com a organização dos tempos, atividades e espaços organicamente vinculados às formas de organização da vida de seus povos, sem, contudo, abrir mão dos conhecimentos acumulados e dos direitos fundamentais válidos para todas as crianças (SILVA e PASUCH, 2010, p. 3-4).

$\mathrm{Na}$ educação infantil ribeirinha, as propostas educativas devem garantir a participação ativa das crianças nas produções na escola e na convivência nos diferentes espaços que o campo proporciona. Na área ribeirinha, há uma especificidade geográfica que rege a organização dos modos de vida dessa população: o contato diário com a água e seus movimentos de cheia e vazante.

Para chegar à escola, as crianças são transportadas na lancha mantida pela SEMED, que faz o trajeto de idas e vindas diariamente das crianças. Em situações atípicas de não funcionamento da lancha por diversos fatores, as famílias usam seus transportes particulares para esse movimento. Geralmente, são pequenas embarcações com motores de rabeta. Existem também as caronas nas lanchas de outras famílias ou outros órgãos públicos. Com todas as dificuldades de acesso vividos pelas famílias que dependem das águas de forma exclusiva para se locomover, há uma rede de apoio entre aqueles que partilham de condições semelhantes. 
No percurso das comunidades onde moram até a escola, as crianças encontram com pessoas de diferentes idades, profissões e comunidades, nas demais lanchas que seguem pelo rio. Alguns são conhecidos "de terra", moradores da mesma comunidade ou de comunidades vizinhas. Outros, conhecidos pelos encontros diários dos percursos que se cruzam pelo rio. $O$ transporte segue seu curso, parando em vários pontos ao longo do rio Tarumã Açú.

Fotografia 1: A volta para casa

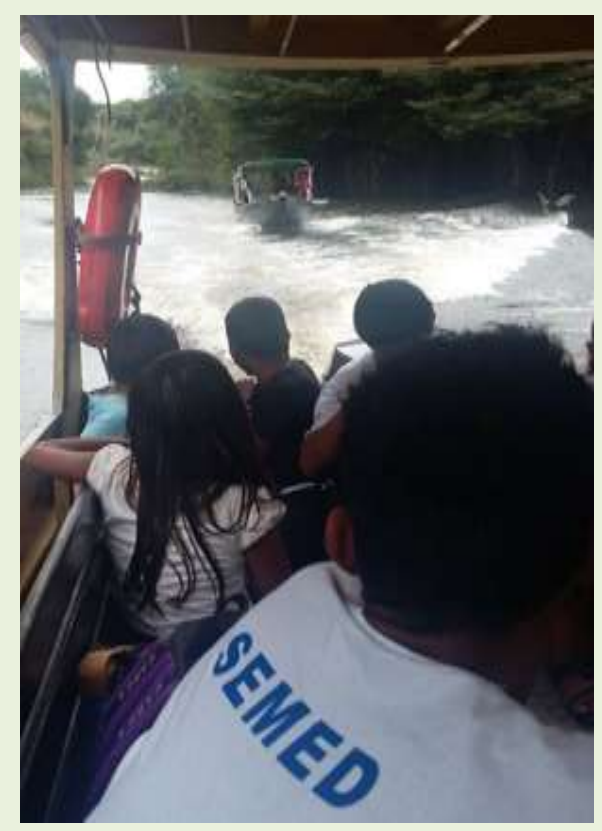

Fonte: Oliveira (2018).

Essas relações durante o trajeto se refletem nos diálogos com a professora e entre as crianças. A garantia de espaço e tempo para que as observações sobre a realidade ribeirinha sejam valorizadas no contexto da escola é muito importante no processo de construção da identidade da criança e no conhecimento sobre o mundo físico, social, ao tempo e a natureza, como nos orienta as DCNEI (BRASIL, 2009b).

Ser professora de educação infantil ribeirinha envolve a complexidade deste equilíbrio: organização de saberes e fazeres com a identidade das infâncias do campo (BRASIL, 2009b) e o acesso ao conhecimento das produções humanas acumuladas ao longo da história (VIGOTSKI, 2012). 
Professores moradores da zona urbana tem o desafio de compreender as especificidades da cultura e modos de vida do/no campo sem impor a lógica de superioridade da vida na cidade. A relação com os tempos, espaços e símbolos ribeirinhos são diferentes, o que tornam os processos de ensino, aprendizagem e desenvolvimento das crianças pequenas ainda mais complexo.

Temas relacionados à infância e o reconhecimento de sua participação na sociedade começaram a ser retratados historicamente desde o período medieval, como apontou Ariès (2011) em sua pesquisa sobre a infância europeia. No Brasil, Kramer (2006), Priore (2000) e Kuhlmann Jr. (1998) produziram importantes e necessárias pesquisas sobre a história da infância nacional.

Quando buscamos pesquisas sobre a história da infância amazônica, nos deparamos com um número ainda tímido de produções. Almeida e Barreto $(2007$, p. 69, 70) sinalizam em sua pesquisa sobre crianças e jovens no Amazonas (compreendendo os séculos XVI a VIX) que

Quando se fala em Amazônia, somos automaticamente arrebatados por um imaginário sustentado pela noção de meio ambiente, biodiversidade, sociodiversidade, desenvolvimento sustentável etc. A literatura científica, amplíssima, reflete bem a fisiografia amazônica, porém, as reflexões sobre as particularidades humanas, em especial sobre a criança amazônica, quase nunca aparecem no centro das investigações. A criança é um sujeito silenciado, particularmente na história da Amazônia. Este silenciamento termina por transformar-se em valioso instrumento no resgate das mentalidades sobre a infância na compreensão do lugar e/ou posição que ela ocupa nos espaços sociais nos vários momentos da história da Amazônia.

Fraxe, Witkoski e Miguez (2009) corrobora com a ideia do silenciamento e invisibilidade que envolve tudo o que consiste o ser da Amazônia, no qual a criança está inserida, quando trata da construção das identidades. Além disso, destaca que a população ribeirinha não está isenta do contato com sociedades urbanas. O rio é caminho de partidas e chegadas onde esses contatos se estabelecem. "Partimos do pressuposto de que o homem amazônico não está cristalizado no tempo, apesar de buscar manter suas 
práticas tradicionais, recebe influências diversas da sociedade urbanoindustrial" (FRAXE; WITKOSKI; MIGUEZ, 2009, p. 31).

Por nascer em um meio cultural, a criança se relaciona com seus aspectos peculiares e vivencia situações de exploração e experimentação. Assim, as relações que ela estabelece no ambiente onde vive, produz experiências fundamentais para o processo de desenvolvimento de diferentes linguagens.

Por experiências, se entende aqui as ações pedagógicas que possibilitam um contexto fortemente educativo, que estimula a criança a dar significado, reorganizar e representar a própria existência. O sentido de experiência aqui empregado também se refere a uma troca ativa com o mundo, provocando transformações no ambiente e nos sujeitos. "Em seu estado máximo, uma experiência se converte para o sujeito da experiência em uma interpretação ampliada sobre o seu eu e o mundo, sobre aquilo que naquele momento significa ser o seu ambiente" (FOCHI, 2015, p. 222).

A escola é o local onde a vida coletiva favorece as interações das crianças em grupo e em atividade sob a orientação do professor, sendo um ambiente que recebe influências das condições sociais e culturais constantemente. Vale frisar que a cultura é, por sua natureza, plural, pois implica na vida em sociedade, constituída por diferentes práticas, costumes, linguagens e modos de viver.

Uma vez compreendido que essas situações contribuem para 0 processo de aprendizagem e desenvolvimento das crianças, é possível atribuir significados no seu espaço na escola e ressignificações da interação no processo educativo. Para Arroyo (2008, p. 110),

uma escola do campo não é, afinal, um tipo diferente de escola, mas sim é a escola reconhecendo e ajudando a fortalecer os povos do campo como sujeitos sociais, que também podem ajudar no processo de humanização do conjunto da sociedade, com suas lutas, sua história, seu trabalho, seus saberes, sua cultura, seu jeito.

Nas experiências concretas do cotidiano, residem situações importantes a serem consideradas e problematizadas para as crianças, tais 
como as atividades de higiene, alimentação e ainda, o convívio no espaço da vida coletiva e nas interações com pessoas de diferentes idades (FOCHI, 2015).

Pensando o dia a dia onde a criança pequena vive e se relaciona com os seus, a discussão Michael de Certeau (2005) sobre a invenção do cotidiano nos ajudam a construir uma ideia de cultura relacionada às minúcias a essa invenção que, por evocar tantos modos de ser e de fazer, torna visível o caráter plural da cultura.

Essa concepção oportuniza uma forma de resistência a um padrão ainda dominante que concebe a cultura nos padrões de instrução ou no consumo de bens. Certeau (2005) ainda pondera que viver é uma relação constante de negociação sobre a validade do cotidiano, porque mesmo que a cultura seja plural, muitas vezes, as diferenças que caracterizam essa pluralidade são desiguais, considerando-se as relações de poder que permeiam a produção da cultura.

Mesmo que a infância não tenha sido o foco dos estudos de Certeau, essa problematização nos ajuda a perceber que os discursos produzidos sobre o lugar da criança no cotidiano são também marcados pela desigualdade da condição social que as crianças pequenas se encontram nos diferentes espaços que ela ocupa (casa, escola, comunidade etc.). Isso precisa ser considerado na defesa de criação de oportunidade para a fala e escuta de crianças pelos adultos na escola.

As sociedades não podem existir sem as crianças. Ser social implica no compartilhamento com elas dos significados e sentidos sobre o mundo, asseverando-se que, sem uma relação ativa na elaboração das falas e das histórias das nossas vivências nos lugares que vivemos, serão sempre falas e histórias incompletas.

Por isso, a formação docente necessita desse olhar para os desafios e possibilidades que compõem a infância do campo e suas especificidades de modo a promover o desenvolvimento integral de todas as crianças da educação infantil e que nela vivenciam suas primeiras experiências com a instituição escolar. 
Como já sinalizamos, o movimento das águas é um fator de grande importância para a organização da escola ribeirinha. Cheias e vazantes são os fatores que incidem desde o calendário escolar, diferente das escolas da zona urbana. Na DDZ Rural nas escolas do rio Negro, o ano letivo inicia em janeiro e finaliza em outubro (conforme o movimento da cheia e vazante, pode haver alterações), época que a vazante chega nos níveis mais críticos, dificultando o acesso a muitas localidades.

A elaboração do calendário escolar municipal, que determina os dias de trabalho no ano escolar e ano letivo' ${ }^{6}$ da área ribeirinha do rio Negro é de responsabilidade da Gerência de Documentação e Auditoria Escolar da SEMED Manaus, que considera o acesso (já que a maior parte das crianças que frequentam a escola vivem em outras comunidades), o movimento das águas e a relação com a natureza que as comunidades dessa área vivenciam.

Em média, apenas $20 \%$ dos alunos matriculados moram na comunidade Nova Esperança. Como não há escola na zona Rodoviária próxima, é a escola da comunidade Esperança que também atende as crianças moradoras dos ramais7 e que são transportadas em micro-ônibus. De responsabilidade do município, conforme parágrafo $3^{\circ}$ do artigo $8^{\circ}$ da Resolução No 2/20088, a SEMED Manaus mantém o micro-ônibus que, durante o ano letivo, transporta os alunos moradores dos ramais de terra ao longo do ramal da Cooperativa, e nos meses de setembro e outubro (quando a vazante se acentua e inviabiliza o transporte pelo rio), transporta também os professores.

Em sua maioria, os professores da escola moram na zona urbana da cidade de Manaus, incluindo o diretor. Somente a professora da turma da

\footnotetext{
6 A diferença vislumbrada no calendário entre o ano escolar e o ano letivo é de que o primeiro se refere ao trabalho pedagógico do professor sem os alunos e o segundo se refere às práticas com alunos.

7 Ramais são estradas (geralmente de terra) que dão acesso a comunidades afastadas das rodovias principais.

8 Esse parágrafo versa o princípio de que a responsabilidade pelo transporte escolar de alunos da rede municipal seja dos próprios municípios. A Resolução citada estabelece diretrizes complementares, normas e princípios para o desenvolvimento de políticas públicas de atendimento da Educação Básica do Campo.
} 
educação infantil reside na comunidade. Para chegar à escola no período de cheia do rio Negro, os professores se deslocam através de canoa com motor de rabeta. A canoa comporta até oito pessoas e parte diariamente da zona oeste da cidade de Manaus às sete horas da manhã, retornando às dezesseis horas.

Fotografia 2: Transporte de acesso dos professores à escola via fluvial por motor de rabeta

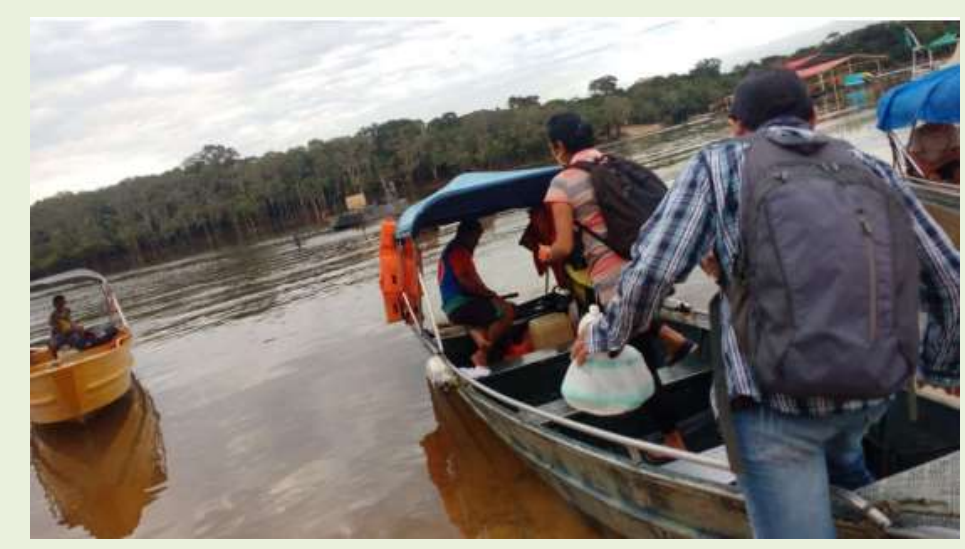

Fonte: Oliveira (2018).

No período da vazante, o acesso dos professores moradores na zona urbana à escola se dá pelo micro-ônibus que atende a zona Rodoviária. Ele parte da zona oeste da cidade de Manaus às quatro horas da manhã e transita pela via de acesso à escola através do ramal da Cooperativa, no km 21 da BR/174, chegando à comunidade Nova Esperança por volta das sete horas da manhã.

No período da cheia, o acesso dos professores que moram na zona urbana dura cerca de quinze minutos. No período da vazante, esse tempo se estende para cerca de três horas. O movimento de construção da identidade do professor ribeirinho começa pelo trajeto. Não são poucos os professores que desistem quando sentem o impacto das condições de acesso às escolas.

Nessa perspectiva, dialogamos com Heller (2000) quando discute que as identidades são modos de afirmação e/ou negação do humano que permitem as interações entre as pessoas. Elas são realizadas simbolicamente nas ações cotidiana e não cotidianas e produzem noções de pertencimento 
como classe, grupo, profissões etc. Essas representações de identidade podem ser entendidas como uma construção simbólica que produz práticas sociais que permitem o posicionamento dos indivíduos na sociedade. Para Heller (2000, p. 17):

\begin{abstract}
A vida cotidiana é a vida de todo homem. Todos a vivem, sem nenhuma exceção, qualquer que seja seu posto na divisão de trabalho intelectual e físico. Ninguém consegue identificar-se com sua atividade humano-genérica a ponto de poder desligar-se inteiramente da cotidianidade. $\mathrm{E}$, ao contrário, não há nenhum homem, por mais "insubstancial" que seja, que viva tão somente na cotidianidade, embora essa o absorva preponderantemente.
\end{abstract}

No cotidiano, produzimos interações com o tempo e o espaço, as relações sociais, os saberes, os desejos, os elementos do imaginário e a cultura, sempre em contato com o outro. Não vivemos sozinhos e isolados. As relações cotidianas se caracterizam pelo modo como os indivíduos vivem as suas vidas pessoal e profissional na coletividade social. O cotidiano se organiza a partir do enraizamento gerado pela vida em sociedade, pela capacidade do homem de se encontrar no mundo e conhecer-se como ser humano pertencente a um grupo, que orienta tanto sua vida individual quanto sua vida coletiva.

Vivenciar o cotidiano escolar ribeirinho no período da pesquisa nos oportunizou enxergar os modos de organização pedagógico e as marcas da cultura tecidas entre os aspectos próprios da localidade e os atravessamentos da cultura urbana, em um movimento não cotidiano de análises, leituras e escrita.

A rotina observada na turma de educação infantil pré-escolar trazia elementos comuns à rotina urbana, como iniciar o encontro entre crianças e professora com um agradecimento a entidade divina pelo acesso à instituição, diálogos sobre o dia anterior, contação de histórias, tempo para o lanche/merenda e tarefas propostas pela professora.

Além da rotina, havia os encontros com a natureza no entorno da escola. Em um dos encontros durante a pesquisa, o tema a ser trabalhado era hábitos de higiene. Estava no planejamento conversar sobre como um 
banho devia ser, a importância de cortar a unhas, de como lavar os cabelos. A proposta foi desenvolvida com a turma indo para o igarapé que corre ao lado da escola, tomar banho juntos, enquanto a professora explicava sobre a importância da higiene.

Fotografia 3: Quando a sala de referência não tem paredes

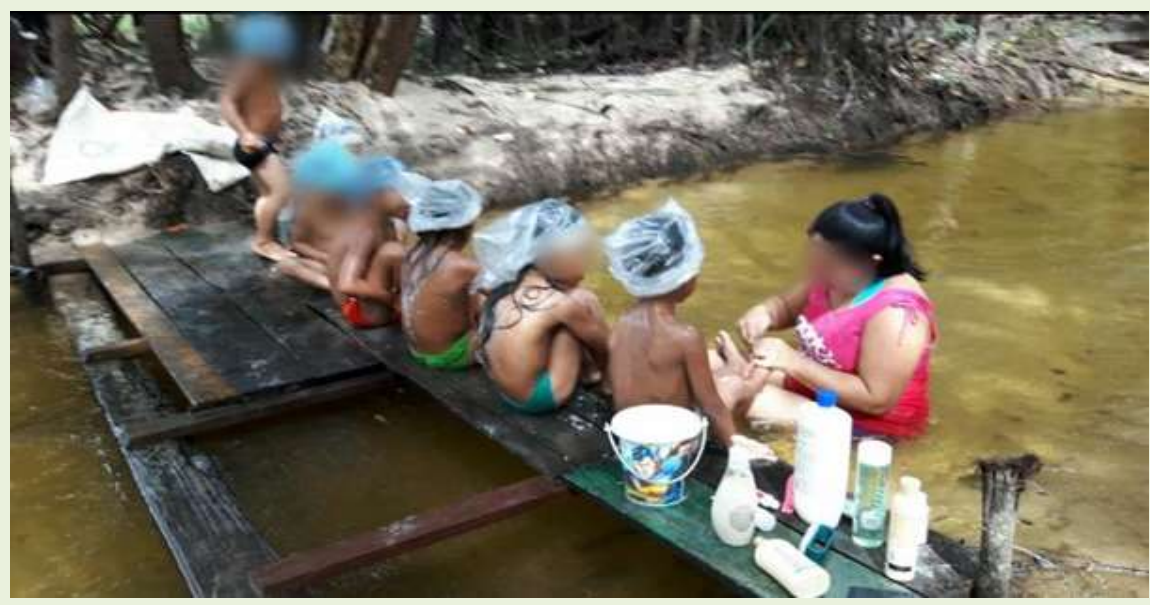

Fonte: Oliveira (2018)

O momento diário de agradecimento à entidade divina, sempre no início das aulas, nos fez refletir sobre o estado laico ${ }^{9}$ e de como a rotina de oração/confessional é presente nas salas de educação infantil (observação de vivências como pedagogas das escolas municipais e nos assessoramentos pedagógicos nas escolas nas divisões distritais da cidade de Manaus). A formação histórica do povo e das escolas brasileiras tem influência religiosa na sua origem, especialmente com a ordem dos jesuítas que chega junto com os portugueses ao Brasil no período colonial. Essa influência cristã se mantém até os dias de hoje10.

9 O artigo 210 da Constituição Federal prevê que o ensino religioso seja oferecido em caráter facultativo nas escolas públicas. O artigo 19 veda à União, aos Estados, ao Distrito Federal e aos Municípios "estabelecer cultos religiosos ou igrejas, subvencioná-los, embaraçar-lhes o funcionamento ou manter com eles ou seus representantes relações de dependência ou aliança, ressalvada, na forma da lei, a colaboração de interesse público". Em respeito à essa vedação, o artigo 33 da LDB prevê que o ensino religioso será oferecido assegurando o "respeito à diversidade cultural religiosa do Brasil, vedadas quaisquer formas de proselitismo".

10 O cristianismo chega ao Brasil junto com portugueses em 1500. Uma das primeiras ações de Pedro Álvares Cabral foi organizar uma missa. Esse processo fixou profundas raízes cristãs em nossa sociedade, que perduram até os dias atuais. Durante o período de colonização, ordens e congregações religiosas assumem serviços nas paróquias e dioceses, na educação

Revista Exitus, Santarém/PA, Vol. 12, p. 01 - 25, e022009, 2022. 
Essas relações são construídas nas vivências com os adultos que também recebem a influência da religião cristã nas suas formações sociais, através do cotidiano vivido e nas manifestações culturais. Entretanto, precisamos considerar que encontramos na escola pública brasileira uma grande heterogeneidade de sujeitos que vivenciam diferentes condições econômicas, sociais, religiosas, étnicas e estéticas. Nas interações com as crianças, essa relação faz parte dos muitos elementos que constrói sua identidade.

Outro aspecto observado foram as falas das crianças com fatos noticiados nos jornais televisivos. Durante os diálogos que estabeleciam entre si ou com professora, traziam os acontecimentos da atualidade, apontando que as zonas rurais não são espaços isolados quanto ao acesso às informações veiculadas pela TV.

Adentrar o dia a dia da escola em uma pesquisa participante, oportunizou a percepção do movimento das construções sociais em que as crianças atuam ativamente, vendo como fazem para participar das atividades que a professora propõe dentro da sala, como agem durante o intervalo para alimentação, como seguem orientações ou observam os pares. Para Heller (1987, p. 21-22):

Todo homem ao nascer se encontra em um mundo já existente, independentemente dele. Este mundo já se apresenta constituído e aqui ele deve conservar-se e dar prova de sua capacidade vital. 0 particular nasce em condições sociais concretas. Antes de tudo, deve aprender a usar as coisas, apropriar-se dos sistemas de usos e dos sistemas de expectativas, isto é, deve conservar-se exatamente no modo necessário e possível em uma época determinada no âmbito de uma camada social dada. Assim, a reprodução do homem particular é sempre a reprodução do homem histórico, de um particular em um mundo concreto.

As crianças se humanizam nas condições que organizamos a educação através do quanto permitimos que sejam sujeitos, já que o processo de humanização é um processo de educação (LEONTIEV, 2004). Ter isso em mente ao elaborar uma proposta de atividade para crianças na

nos colégios e na evangelização dos indígenas, inserindo-se em definitivo na formação social brasileira (PRIORE, 2004).

Revista Exitus, Santarém/PA, Vol. 12, p. 01 - 25, e022009, 2022. 
educação infantil coloca o professor no desafio humanizador do seu fazer, que é o de contemplar a criança enquanto sujeito ativo do seu desenvolvimento e com ela produzir cultura na sociedade em que vive, marcada por diversidade e complexidade nas relações sociais dentro e fora da escola.

Para a teoria Histórico-Cultural, o processo de aprender envolve um triplo protagonismo em que a criança, a cultura e nós, professoras e professores, ocupamos papel principal. As crianças aprendem quando são sujeitos das situações vividas. Isso requer que se organize espaço, tempo, relações e atividades de modo a promover o agir das crianças em detrimento de posturas passivas. Essa organização requer, por sua vez, não somente oportunizar a fala das crianças, mas a escuta respeitosa, considerando suas posições e seus desejos. Escuta como metáfora de disponibilidade.

Fundamentada na perspectiva da teoria histórico-cultural, sobretudo nas ideias de Vigotski $(2012,2014)$, a análise dos significados construídos pelas crianças pequenas da educação infantil ribeirinha se relaciona com as vivências e experiências cotidianas na escola e fora dela. Tomando como base a fala das crianças na atividade dialógica com a pesquisadora e as observações das brincadeiras iniciadas e conduzidas por elas, estar na escola, para elas, pressupõe estar com seus colegas e partilhar dessas vivências e experiências, seja nas tarefas propostas pela professora, seja nos significados partilhados nas rotinas.

Falar de nós, professoras e professores, pedagogas e pedagogos, como organizadores do ambiente educativo, está para além de organizar o espaço para receber crianças. Nos coloca na responsabilidade de pensar cada canto e objeto da sala como promotor do desenvolvimento humano, planejando esse espaço no coletivo com outros professores e professoras e com as crianças, de maneira que as especificidades de suas vivências ribeirinhas sejam consideradas, como aponta o Parecer CNE/CEB N²0/2009: 
Uma política que promova com qualidade a Educação Infantil nos próprios territórios rurais instiga a construção de uma pedagogia dos povos do campo - construída na relação intrínseca com os saberes, as realidades e temporalidades das crianças e de suas comunidades - e requer a necessária formação do professor nessa pedagogia (BRASIL, 2009a, p. 12).

\section{CONSIDERAÇÕES FINAIS}

É preciso enxergar a potência de cada criança como capaz de se humanizar nas condições de vida e cultura que estão inseridas, valorizando suas aprendizagens coletivas e ampliando suas referências acerca do mundo. O olhar atento das professoras e professores que compartilham esse momento da vida em processo necessita de uma formação sensível de acolhimentos dos afetos, falas, gestos, desenhos e brincadeiras que refletem as linguagens empregadas pelas crianças para apreender $o$ mundo $e$ expressar aquilo que sabem sobre ele.

O processo formativo de professores deve considerar que cada pessoa, ao passar por um curso de licenciatura, saia dele com as condições de entender como as pessoas aprendem e se desenvolvem e como organizar as condições para que o processo de humanização aconteça.

A educação infantil carrega em si um mundo de complexidades que exigem profunda reflexão sobre os saberes e as potências de bebês e crianças. Precisamos continuar trabalhando para superar a ideia das escolas de primeira infância como um tempo de preparação para o processo de alfabetização no ensino fundamental, e jogar cada vez mais luz na defesa de uma proposta pedagógica que respeite os direitos da criança tendo como eixo as interações e a brincadeira, entendendo a brincadeira como expressão das culturas infantis.

Quando decidimos produzir pesquisas sobre a realidade local, muitas vezes desconhecidas pelo restante do país, desejamos ampliar o debate sobre as infâncias amazônicas para entendermos cada vez mais como se organizam suas dinâmicas e como podemos ser melhores profissionais para atuar junto às crianças, que contam com o nosso apoio para desvelar o mundo e aprender sobre ele. 
Nas escolas ribeirinhas, a relação com a natureza compõe as relações cotidianas de vida. Essas experiências corpóreas, sensíveis, sociais e afetivas, vão constituindo os recursos de ação e interação das crianças com o seu meio, e sobre o qual o professor ou a professora precisam considerar no momento de organizar o fazer pedagógico.

No espaço escolar, os intercâmbios entre os saberes e fazeres do local articulam-se com o global. Do ponto de vista da constituição da identidade da criança ribeirinha, os fazeres pedagógicos devem respeitar e trabalhar as diversidades e dinâmicas próprias dos sujeitos como forma de enriquecer a aprendizagem e construir novas práticas sociais e igualitárias, sedimentadas no respeito ao outro, como afirma Santos (2003, p. 56):

Temos o direito a ser iguais quando a nossa diferença nos inferioriza; e temos o direito a ser diferentes quando a nossa igualdade nos descaracteriza. Daí a necessidade de uma igualdade que reconheça as diferenças e de uma diferença que não produza, alimente ou reproduza as desigualdades.

Cabe aos adultos e pessoas mais experientes a tarefa de cuidar/educar, promovendo experiências que permitem às crianças se constituírem pessoas numa perspectiva de emancipação. Para a educação infantil ribeirinha, considerar que cada criança tem um contexto na zona rural, é compreender que as infâncias são compostas por experiências diferentes e demandam outras experiências geradas a partir das dinâmicas culturais específicas.

Esperamos ampliar a rede de debates ao compartilhar as narrativas vividas e as reflexões e discussões geradas sobre a educação infantil ribeirinha nesse processo. Desejamos continuar ampliando nosso olhar para observar atentamente as formas de relações construídas de forma peculiar na região em que vivemos a fim de alargarmos a rede de estudos e pesquisas da infância amazônica, enxergando a criança como sujeito "histórico e de direitos que, nas interações, relações e práticas cotidianas que vivencia, constrói sua identidade pessoal e coletiva, brinca, imagina, fantasia, deseja, aprende, observa, experimenta, narra, questiona e constrói 
sentidos sobre a natureza e a sociedade, produzindo cultura" (BRASIL, $2009 b)$.

\section{REFERÊNCIAS}

ALMEIDA, S. V.; BARRETO, M. G. C. (orgs.). Crianças e jovens no Amazonas (XVIXIX): imaginários e representações históricas. Manaus: UEA, 2007.

ALMEIDA, S. V.; BARRETO, M. G. C. (orgs.). Outros sujeitos, outras pedagogias. Petrópolis: Vozes, 2012.

ARIÈS, P. História social da criança e da família. Trad. Dora Flaksman. 2 ed. Rio de Janeiro: LTC, 2011.

ARROYO, M. G.; CALDART, R. S.; MOLINA, M. C. (orgs.). Por uma educação do campo. 3 ed. Petrópolis: Vozes, 2008.

BENCHIMOL, S. Amazônia: formação social e cultural. 3 ed. Manaus: Valer, 2009.

BRASIL. Parecer CNE/CEB 20/2009. Revisão das Diretrizes Curriculares Nacionais para a Educação Infantil. Brasília: MEC, SEB, 2009a.

BRASIL. Resolução n 5 de 17 de dezembro de 2009. Estabelece as Diretrizes Curriculares Nacionais para a Educação Infantil - DCNEI. Brasília: MEC, SEB, $2009 b$.

BRASIL. Resolução CNE/CEB 2/2008. Diário Oficial da União. Brasília, 29 de abril de 2008. Seção I, p. 25. Estabelece diretrizes complementares, normas e princípios para o desenvolvimento de políticas públicas de atendimento da Educação Básica do Campo. Brasília: MEC, SEB, 2008.

CERTEAU, M. A Cultura do Plural. Campinas: Papirus, 2005.

CHAVES, M. P. S. R. Uma experiência de pesquisa-ação para gestão comunitária de tecnologias apropriadas na Amazônia: o estudo de caso do assentamento de Reforma Agraria Ipora. Tese Doutorado em Política Cientifica e Tecnologia Universidade Estadual de Campinas. Campinas - SP, 2001.

FRAXE, T. J. P.; WITKOSKI, A. C.; MIGUEZ, S. F. O Ser da Amazônia: identidade e invisibilidade. Cienc. Cult. Vol. 61. № 3. São Paulo, 2009. Disponível em: <http://cineciaecultura.bvs.br/scielo.php?script=sci_arttext\&pid=S0009>. Acesso em: 10 jun. 2020.

FOCHI, P. S. Ludicidade, continuidade e significatividade nos campos de experiência. In: FINCO, D.; BARBOSA, M. C. S.; FARIA, A. L. G. Campos de Experiência na Escola da Infância: contribuições italianas para inventar um currículo de educação infantil brasileiro. Campinas: Edições Leitura Crítica, 2015. 
HELLER, A. O cotidiano e a história. Trad. Carlos Nelson Coutinho. 6 ed. São Paulo: Paz e Terra, 2000.

HELLER, A. Sociología de la vida cotidiana. 2 ed. Barcelona: Ediciones Península, 1987.

KRAMER, S. A política do pré-escolar no Brasil: a arte do disfarce. 8 ed. São Paulo: Cortez, 2006.

KUHLMANN JR., M. Infância e educação infantil: uma abordagem histórica. 2 ed. Porto Alegre: Mediação, 1998.

MANAUS. Conselho Municipal de Educação. Secretaria Municipal de Educação. Proposta Pedagógico-Curricular de Educação Infantil. SEMED: Manaus, 2016.

LEONTIEV, A. N. O homem e a cultura. In: LEONTIEV, A. N. O desenvolvimento do psiquismo. Trad. Rubens Eduardo Frias. 2 ed. São Paulo: Centauro, 2004.

OLIVEIRA, A. P. L. C. Os significados construídos pelas crianças da educação infantil ribeirinha de Manaus. $116 f$. Dissertação (Mestrado em Educação) Faculdade de Educação, Universidade Federal do Amazonas, Manaus, 2018.

PRIORE, M. D. (org.). História das crianças no Brasil. 4 ed. São Paulo: Contexto, 2004.

SANTOS, B. S. Reconhecer para libertar: os caminhos do cosmopolitanismo multicultural. Rio de Janeiro: Civilização Brasileira, 2003.

SILVA, T. M. D.; PASUCH, J. A importância da Educação Infantil na constituição da identidade das crianças como sujeitos do campo. In: BARBOSA, M. C. S. Oferta e Demanda de Educação Infantil do Campo. Porto Alegre: Evangraf, 2012.

VIGOTSKI, L. S. Obras escogidas II: pensamento y lenguage conferencias sobre Psicologia. Madrid: Machado, 2014.

VIGOTSKI, L. S. Obras escogidas III: problemas del desarollo da la psique. Madrid: Machado, 2012.

Recebido em: 12 de setembro de 2021 . Aprovado em: 02 de dezembro de 2021 .

Publicado em: 07 de janeiro de 2022. 